\title{
Relationship between Serum Hyaluronic Acid Level and Patient Prognosis in Hepatocellular Carcinoma Patients Who Underwent Hepatectomy
}

\author{
Atsushi Nanashima*, Takafumi Abo, Goushi Murakami, Masaki Kunizaki, \\ Hiroaki Takeshita, Shigekazu Hidaka, Kazuo To, Tomoshi Tsuchiya, Takeshi Nagayasu \\ Division of Surgical Oncology, Department of Surgery, Nagasaki University Graduate School of Biomedical Sciences, Nagasaki, Japan. \\ Email: *a-nanasm@nagasaki-u.ac.jp, tac-a@pop11.odn.ne.jp, mkgsmkgs@yahoo.co.jp, masaki2002@yahoo.co.jp, \\ takehiro@nagasaki-u.ac.jp, hidaka-s@nagasaki-u.ac.jp, tokazu@nagasaki-u.ac.jp, tomoshi@nagasaki-u.ac.jp, \\ nagayasu@nagasaki-u.ac.jp
}

Received November $23^{\text {rd }}, 2012$; revised December $21^{\text {st }}, 2012$; accepted December $30^{\text {th }}, 2012$

\begin{abstract}
We examined the relationship between hyaluronic acid (HA) and tumor-related factors after hepatectomy in 158 patients with hepatocellular carcinoma (HCC) who underwent hepatectomy. We examined serum HA levels before hepatectomy by evaluating data for clinicopathological parameters, surgical records, postoperative complications and survival. The mean HA level was $190 \pm 202 \mathrm{ng} / \mathrm{ml}$. Patients were divided into 3 groups: group A had serum HA levels less than $50 \mathrm{ng} / \mathrm{ml}$ (normal range), group B had levels between 50 and $190 \mathrm{ng} / \mathrm{ml}$, and group C had levels over 190 $\mathrm{ng} / \mathrm{ml}$. Group $\mathrm{C}$ had a higher rate of poor liver function compared to others. Multiple tumors were significantly more frequent in groups $\mathrm{B}$ and $\mathrm{C}$ compared to $\mathrm{A}$. The grade of fibrosis and the inflammatory responses were positively correlated with the serum HA level. Postoperative long-term ascites was significantly more frequent in group C compared to others. Although the recurrence rate and the relapse-free period were not significantly related to the serum HA level, the serum HA level was significantly associated with overall survival after hepatectomy $(\mathrm{p}<0.05)$. Cox's multivariate analysis did not show a significant relationship between HA level and survival. Serum HA reflects progression and survival in HCC patients.
\end{abstract}

Keywords: Hepatocellular Carcinoma; Hepatectomy; Serum Hyaluronic Acid Level; Prognosis

\section{Introduction}

Hepatic resection is still the most curative treatment for hepatocellular carcinoma (HCC) [1]. However, tumor recurrence is frequent, and some patients have a poor prognosis [2]. Some factors associated with patient survival have been identified [3-5]. Markers of poor hepatic function and tumor-related factors are significantly associated with tumor recurrence and lower survival [6-8]. Our previous study showed that an advanced grade of hepatic fibrosis, hepatitis, postoperative long-term ascites or postoperative levels of alpha-feto protein (a marker of chronic hepatitis) were significantly associated with shorter survival due to carcinoma after hepatectomy [911]. Deteriorated liver function and co-existing hepatitis would influence tumor progression and subsequent carcinogenesis. Therefore, reliable functional parameters identifying deteriorated liver function or postoperative hepatic complications would be useful to predict postop-

"Corresponding author. erative survival in HCC patients.

The serum hyaluronic acid (HA) level is a well-known marker of hepatic fibrosis and hepatic sinusoidal endothelial function $[12,13]$. Our previous study also showed that HA was significantly associated with poor hepatic function and postoperative complications such as longterm ascites and hepatic fibrosis $[14,15]$. HA might be the most important factor related to poor hepatic functional reserve [16]. Therefore, we hypothesized that the serum HA level, which is a marker of reliable hepatic function, could be applied to predict patient survival in HCC patients. To our knowledge, the relationship between the serum HA level and postoperative prognosis in HCC patients has not been examined. Identification of the relationship between non-tumor related factors and survival is useful to predict patient prognosis. We retrospectively examined the relationship between the serum HA level and clinicopathological factors, postoperative course, tumor recurrence and patient survival in 156 patients with $\mathrm{HCC}$ who underwent hepatectomy. 


\section{Methods}

\subsection{Patients}

This study examined 156 patients with HCC who were scheduled for surgery and admitted to the Division of Surgical Oncology at Nagasaki University Graduate School of Biomedical Sciences (NUGSBS) between 1996 and 2010. Patients with distant metastasis were excluded from the present study. The patients included 121 males and 35 females with a mean age at the time of surgery of $66.6 \pm 10.0$ years $( \pm \mathrm{SD}$, range $28-84$ years). Twenty-three patients had normal livers, and several patients had background liver disease, including alcoholic liver dysfunction in 9 patients, non-alcoholic liver dysfunction in 4 patients, and chronic viral hepatitis in 120 patients (including hepatitis B in 47 patients, hepatitis C in 55 patients and co-existing hepatitis $\mathrm{B}$ and $\mathrm{C}$ in 18 patients). Liver cirrhosis was observed in 56 patients $(37 \%)$. The operative procedures included hemihepatectomy or more extensive hepatectomy in 49 patients, segmentectomy or sectionectomy in 55 patients and partial resection in 52 patients. Radical hepatectomy was performed, and hepatic tumors were completely resected without macroscopic exposure of the amputated section to the remaining liver.

After primary treatment, serum levels of AFP and PIVKA-II were measured every 3 months, and enhanced computed tomography of the liver was obtained every 6 months for at least the first 5 years after hepatectomy in order to monitor the tumor recurrence. The minimum follow-up period after the hepatic resection of HCC was 12 months (range 12 - 78 months). Fifty-two of the 156 (33\%) patients who survived were lost to follow-up, 99 patients died of cancer, and 5 patients died of unrelated diseases. Because these deaths were not cancer-related, data from these 5 patients were excluded.

All study protocols were approved by the Human Ethics Review Board of our institution. Informed consent for data collection was obtained from each patient during this period. Anesthesia data and patient data were retrieved from the NUGSBS database.

\subsection{Measurement of Tumor Markers and Histological Findings}

Clinicopathological patient data was retrieved from the archives at our institute. The PIVKA-II level was examined by an enzyme-linked immunoassay using Eitest $^{\mathbb{B}}$ PIVKA-II (Sanko Junyaku Co., Tokyo, Japan). In our hospital, the normal value of AFP in patients with HCC is less than $20 \mathrm{ng} / \mathrm{mL}$. The reported normal value of PIVKA-II is $<40 \mathrm{mAU} / \mathrm{ml}$. Elevated levels of AFP and PIVKA-II were defined as those exceeding the normal levels. The tumor-related factors were compared to the findings from the histopathological examination of the resected specimen. For assessment, we used the rules laid out by the Liver Cancer Study Group of Japan for the classification of primary liver cancer [17].

\subsection{Measurement of Serum HA}

Peripheral blood samples were collected from each patient in the early morning before surgery, when the patient was in stable condition. The blood sample was centrifuged at $3000 \mathrm{rpm}$ for 15 minutes, and serum was stored at $-80^{\circ} \mathrm{C}$. HA was assayed using the sandwich binding protein assay by SRL, Inc. (Tokyo, Japan). The normal value for the serum HA level reported by SRL, Inc. is less than $50 \mathrm{ng} / \mathrm{ml}$. The staging of the tumor, the grading score for hepatic fibrosis and the histologic activity index (HAI) score as defined by Knodell et al. [18] were used for the histopathological evaluation.

\subsection{Statistical Analysis}

Differences in categorical data between groups and differences in prevalence were assessed by the chi-square test, Fischer's exact test or Dunnett's multiple comparison test. Differences in continuous data between groups were evaluated by Student's $t$-test or the Mann-Whitney test. The disease-free interval and overall survival were calculated using the Kaplan-Meier method, and differences between groups were tested for significance using the log-rank test. Multivariate analysis was performed using Cox's proportional hazards regression modeling. A two-tailed $P$ value of $<0.05$ was considered significant. Statistical analyses were performed using the SAS software (Statistical Analysis System Inc., Cary, NC).

\section{Results}

\subsection{Perioperative Parameters}

According to the Child-Pugh classification, 143 (92\%) patients were classified as $\mathrm{A}$, and 13 patients were classified as B. The mean alpha-feto protein (AFP) level was $7411 \pm 48,724 \mu \mathrm{g} / \mathrm{ml}$ (median 67), and the mean protein-induced vitamin $\mathrm{K}$ antagonist and agonist (PIVKA)II level was $7593 \pm 24,764 \mu \mathrm{g} / \mathrm{ml}$ (median 346). The pathological tumor node metastasis (TNM) stage of HCC according to the Liver Cancer Study Group of Japan was stage I in 10 patients $(6 \%)$, stage II in 60 patients (39\%), stage III in 50 patients (32\%) and stage IVA in 38 patients (23\%). A solitary tumor was found in 110 patients $(65 \%)$, and 46 patients had multiple tumors. The size of the tumor was less than $2 \mathrm{~cm}$ in 24 patients (15\%), $2-5$ $\mathrm{cm}$ in 72 patients $(46 \%)$, and greater than $5 \mathrm{~cm}$ in 60 patients $(39 \%)$. Vascular tumor thrombus was observed in 58 patients $(37 \%)$. Transarterial chemoembolization or thermal ablation pretreatment was performed in 40 patients $(26 \%)$. The mean hyaluronic acid (HA) level was 
$190 \pm 202 \mathrm{ng} / \mathrm{ml}$ (range 9 - $1356 \mathrm{ng} / \mathrm{ml}$, median 128 $\mathrm{ng} / \mathrm{ml})$. The patients were divided into 3 groups: group A had serum HA levels less than $50 \mathrm{ng} / \mathrm{ml}$ (normal), group $\mathrm{B}$ had levels between 50 and $190 \mathrm{ng} / \mathrm{ml}$, and group $\mathrm{C}$ had levels over $190 \mathrm{ng} / \mathrm{ml}$.

The stage of histological fibrosis was 0 in 5 patients (4\%), 1 in 28 patients $(21 \%), 2$ in 19 patients $(14 \%), 3$ in 40 patients $(30 \%)$ and 4 (cirrhosis) in 43 patients $(32 \%)$. The mean blood loss was $1160 \pm 678 \mathrm{ml}$, and blood loss over $1500 \mathrm{ml}$ was observed in 28 patients $(18 \%)$. A blood transfusion was performed in 58 patients (37\%). After hepatectomy, hepatic failure occurred in 8 patients (5\%), and long-term ascites was observed in 45 patients $(29 \%)$.

\subsection{Relationship between Clinicopathological Parameters and Serum HA Level}

In the 158 patients, age and the serum HA level were not significantly correlated with gender or the conventional tumor markers for HCC (Table 1). Group C showed a significantly higher rate of poorer liver function (Child classification B or Liver Damage grade B) compared to groups A or B. Groups B and C had significantly higher rates of viral chronic hepatitis compared to group A. Multiple tumors were significantly more frequent in groups $\mathrm{B}$ and $\mathrm{C}$ than in group $\mathrm{A}$, but there were no significant differences in tumor size, vascular involvement, macroscopic finding or TNM stage among the groups. Concerning the non-tumor liver parenchyma, the scores for staging, which reflect the grade of fibrosis, and grading, which reflects the grade of inflammatory response, were positively correlated with the serum HA level, and these results were significant. More extensive hepatectomy was significantly more frequent in group A compared to groups B or C. Intraoperative blood loss was not significantly different between the groups. Postoperative long-term ascites, even with the use of diuretics, was significantly more frequent in group $\mathrm{C}$ than in groups $\mathrm{A}$ or $\mathrm{B}$. Hepatic failure tended to be more frequent in group $\mathrm{C}$ than in groups $\mathrm{A}$ or $\mathrm{B}$, but this trend was not significant.

\subsection{Relationship between Preoperative Hyaluronic Acid Levels and Incidence of Tumor Recurrence/Post-Treatment Survival}

The 1- and 3-year survival rates were $59 \%$ and $36 \%$, respectively, and the median survival period was 40.2 months. The 3-, 5- and 8-year survival rates were 55\%, $40 \%$ and $26 \%$, respectively, and the median survival period was 62.7 months. The tumor recurrence rate was not significantly related to the level of serum HA, and the serum HA level was not significantly associated with tumor-free survival after hepatectomy (Table 2 and Figure 1(a)). However, the serum HA level was signifi-

Table 1. Relationship between hyaluronic acid levels and patient demographics, clinicopathological parameters and posttreatment tumor recurrence.

\begin{tabular}{|c|c|c|c|c|}
\hline & Group $A^{1)}(n=25)$ & Group $B^{2)}(n=81)$ & Group $C^{3)}(n=50)$ & $\mathrm{P}$ value \\
\hline Gender (male/female) & $21 / 4$ & $63 / 18$ & $37 / 13$ & 0.31 \\
\hline Age & $62 \pm 10$ & $66 \pm 9$ & $69 \pm 10$ & n.s \\
\hline $\operatorname{AFP}(u g / m L)$ & $1048 \pm 3207$ & $1797 \pm 4626$ & $1478 \pm 8232$ & n.s \\
\hline PIVKA-II (mAU/ml) & $550 \pm 1259$ & $747 \pm 2852$ & $882 \pm 2371$ & n.s \\
\hline Child-Pugh (A/B) & $24 / 1$ & $81 / 0$ & $38 / 12$ & $<0.001$ \\
\hline Liver Damage Grade (A/B) & $22 / 3$ & $72 / 9$ & $27 / 23$ & $<0.001$ \\
\hline Viral status (None/B/C/B\&C) & $8 / 8 / 7 / 2$ & $21 / 29 / 24 / 7$ & $5 / 11 / 25 / 9$ & 0.016 \\
\hline Pre-treatment (No/Yes) & $21 / 4$ & $57 / 24$ & $38 / 12$ & 0.32 \\
\hline Number of tumors (solitary/multiple) & $23 / 2$ & $53 / 28$ & $26 / 24$ & 0.009 \\
\hline Tumor size $(<2 / 2-5 / \geq 5 \mathrm{~cm})$ & $2 / 11 / 12$ & $13 / 35 / 33$ & $9 / 25 / 16$ & 0.61 \\
\hline Vascular involvement (No/Yes) & $18 / 7$ & $48 / 33$ & $30 / 18$ & 0.53 \\
\hline Macroscopic finding (S/SC/C) & $12 / 8 / 5$ & $26 / 23 / 32$ & $14 / 17 / 19$ & 0.35 \\
\hline TNM classification $(1 / 2 / 3 / 4 a)$ & $1 / 17 / 4 / 3$ & $5 / 27 / 33 / 17$ & $4 / 17 / 14 / 15$ & 0.12 \\
\hline Staging $(0 / 1 / 2 / 3)$ & $2 / 13 / 3 / 6 / 0$ & $3 / 12 / 14 / 20 / 21$ & $0 / 3 / 3 / 15 / 22$ & $<0.001$ \\
\hline Grading $(0 / 1 / 2$ or more $)$ & $5 / 15 / 5$ & $9 / 35 / 37$ & $2 / 7 / 41$ & $<0.001$ \\
\hline \multicolumn{5}{|l|}{ Operative procedure } \\
\hline $\begin{array}{l}\text { Partial/segmentectomy or sectionectomy/ hemihepatec } \\
\text { tomy or more }\end{array}$ & $3 / 16 / 6$ & $22 / 27 / 32$ & $27 / 12 / 11$ & $<0.001$ \\
\hline Blood loss $>1500 \mathrm{ml}$ & $3(12)$ & $13(16)$ & $12(24)$ & 0.29 \\
\hline Long-term ascites ( $>2$ weeks) & $4(16)$ & $19(24)$ & $25(50)$ & 0.011 \\
\hline Hepatic failure & 0 & $2(3)$ & $6(12)$ & 0.069 \\
\hline
\end{tabular}

Clinicopathological findings and TNM classification were based on the General Rules for the Clinical and Pathological Study of Primary Liver Cancer (17). Parenthesis shows percentage. For abbreviations, see Table 1. n.s; not significant with p value $>0.05$ by the Scheffe's multi-comparison test. 
Table 2. Relationship between pretreatment AFP as well as PIVKA-II and post-treatment tumor recurrence.

\begin{tabular}{cccc}
\hline & $\begin{array}{c}\text { No recurrence } \\
(\mathrm{n}=62)\end{array}$ & $\begin{array}{c}\text { Recurrence } \\
(\mathrm{n}=94)\end{array}$ & $\mathrm{p}$ Value \\
\hline Serum HA level $(\mathrm{ng} / \mathrm{mL})$ & & & \\
$<50$ & 14 & 11 & 0.19 \\
$50-190$ & 29 & 52 & \\
$>190$ & 19 & 31 & \\
\hline
\end{tabular}

AFP, alpha-fetoprotein; PIVKA-II, protein induced by vitamin $\mathrm{K}$ antagonist or agonist.

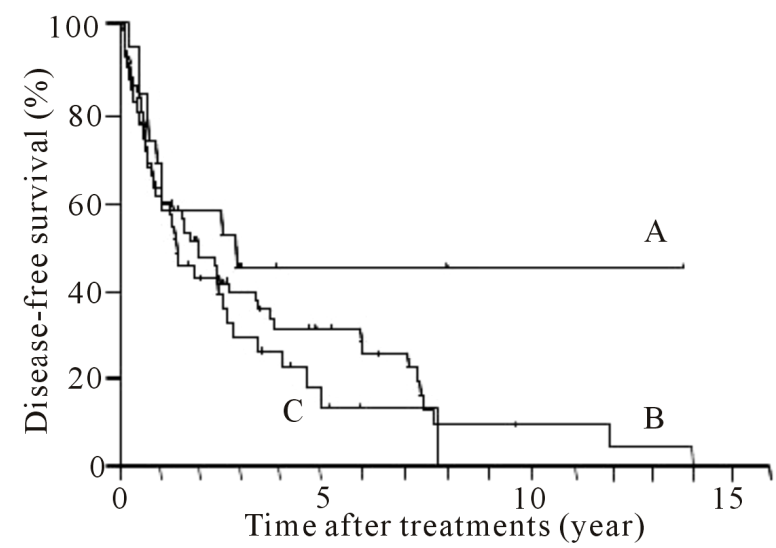

$\begin{array}{llccl}\text { HA }(\mathrm{ng} / \mathrm{ml}) & 3- & 5 \text {-years } & \text { MSP (months) } & \text { p value } \\ \text { A: }<50 & 44 \% & 44 \% & 74 & \\ \text { B: } 50-190 & 41 \% & 6 \% & 42 & 0.26 \\ \text { C: }>190 & 29 \% & 13 \% & 29 & \end{array}$

(a)

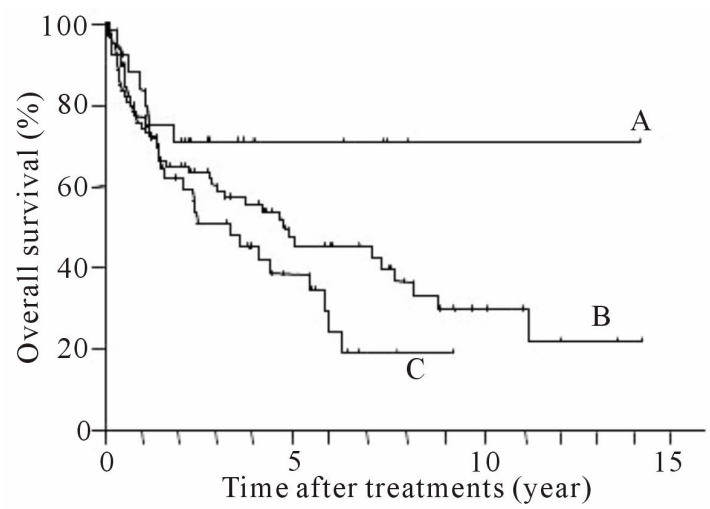

$\begin{array}{lllccc}\text { HA (ng/ml) } & 3- & 5- & 8 \text {-years } & \text { MSP (months) p value } \\ \text { A: }<50 & 69 \% & 69 \% & 69 \% & 123 & 0.049 \\ \text { B: } 50-190 & 64 \% & 46 \% & 46 \% & 78 & \\ \text { C: }>190 & 51 \% & 39 \% & 20 \% & 50 & \end{array}$

(b)

Figure 1. Post-hepatectomy (A) tumor-free and (B) overall survival period for each level of preoperative serum hyaluronic acid (HA) level. Survival rate and median survival period were indicated.

cantly associated with overall survival after hepatectomy (Figure 1(b)) $(\mathrm{p}<0.05)$. Group A had the best prognosis, and group $\mathrm{C}$ had the worst survival after hepatectomy in comparison with the other groups.

\subsection{Cox's Multivariate Regression Analysis for Disease-Free and Overall Survival Rates and Serum HA Levels}

Table 3 shows the significant prognostic factors (identified by univariate analysis) associated with tumor-free and overall survival rates, including changes in the AFP and PIVKA-II levels. The number, size and vascular involvement of tumors were independently associated with disease-free survival. Increased blood loss tended to be associated with poor survival, but this association was not significant. The number of tumors, the tumor size and poor liver function were independently associated with overall survival. Serum HA levels were not significantly associated with disease-free and overall survival in our series.

\section{Discussion}

Specific HCC markers, such as PIVKA-II or AFP levels, are commonly used in Japan for the diagnosis of HCC or for the evaluation of tumor aggressiveness [19-23]. It has been reported that high values of these preoperative markers reflect the prognosis for HCC patients who undergo hepatectomy [24]. Monitoring sensitive markers such as these might be useful for predicting tumor recurrence after hepatectomy [25,26]. Our previous study showed that changes in PIVKA-II or AFP levels were significantly correlated with prognosis in $\mathrm{HCC}$ patients undergoing hepatectomy [11]. In addition to these conventional markers, new biomarkers of HCC have been proposed, $[27,28]$ most of which are HCC specific. The measurement of tumor-specific biological markers can be useful after curative treatments, and it is, therefore, necessary to identify new markers.

In addition to tumor-specific markers, liver function, surgical records or outcomes might be closely related to the prognosis of HCC patients after hepatectomy [6-8]. We reported that non-tumor related parameters, such as hepatic fibrosis and postoperative long-term ascites, were associated with poor survival $[9,10]$. The serum HA level might reflect non-parenchymal liver function or the risk of ascites [14,15]. Measurement of serum HA level has been used as a marker for evaluating liver damage in people with various liver diseases and in patients who receive physically invasive treatments. Serum HA or its protein complex was increased in cancer patients with HCC or other malignancies $[29,30]$. The mechanism for the relationship between HA and tumor progression has not been clarified. Mizuguchi et al. reported that physiological stress might stimulate the production of liverderived growth factors and induce subsequent tumor 
Table 3. Multivariate analysis of prognostic factors influencing tumor-free and overall survival using Cox's proportional hazard test.

\begin{tabular}{|c|c|c|c|c|}
\hline \multirow{2}{*}{ Variables } & \multicolumn{2}{|c|}{ Tumor-free survival } & \multicolumn{2}{|c|}{ Overall survival } \\
\hline & $\mathrm{RR}^{*}(95 \% \mathrm{CI})$ & $\mathrm{p}$ value & $\mathrm{RR}(95 \% \mathrm{CI})$ & $\mathrm{p}$ value \\
\hline \multicolumn{5}{|c|}{ Number of tumors } \\
\hline \multicolumn{5}{|l|}{ Solitary } \\
\hline Multiple & $3.24(2.04-2.93)$ & $<0.001$ & $2.66(1.63-4.34)$ & $<0.001$ \\
\hline \multicolumn{5}{|c|}{ Size of tumor } \\
\hline \multicolumn{5}{|l|}{$<2 \mathrm{~cm}$} \\
\hline $2-5 \mathrm{~cm}$ & $1.85(0.91-3.79)$ & 0.092 & $1.07(0.49-2.34)$ & 0.87 \\
\hline$\geq 5 \mathrm{~cm}$ & $1.97(0.93-4.15)$ & 0.077 & $2.75(1.22-6.18)$ & 0.014 \\
\hline \multicolumn{5}{|c|}{ Vascular involvement (No/Yes) } \\
\hline \multicolumn{5}{|l|}{ No } \\
\hline Yes & $1.71(1.03-2.83)$ & 0.037 & $1.08(0.62-1.87)$ & 0.78 \\
\hline \multicolumn{5}{|c|}{ Liver Damage Grade } \\
\hline \multicolumn{5}{|l|}{ A } \\
\hline B & $1.63(0.95-2.82)$ & 0.14 & $2.27(1.24-4.16)$ & 0.008 \\
\hline \multicolumn{5}{|c|}{ Blood loss (ml) } \\
\hline \multicolumn{5}{|l|}{$<1000$} \\
\hline$\geq 1000$ & $1.70(0.98-2.58)$ & 0.078 & $1.09(0.60-1.99)$ & 0.78 \\
\hline \multicolumn{5}{|c|}{ Alpha-feto protein (ug/ml) } \\
\hline \multicolumn{5}{|l|}{$<200$} \\
\hline$\geq 200$ & $1.00(0.63-1.61)$ & 0.98 & $1.09(0.64-1.85)$ & 0.74 \\
\hline \multicolumn{5}{|c|}{ Pretreatment PIVKA-II (ng/ml) } \\
\hline \multicolumn{5}{|l|}{$<40$} \\
\hline$\geq 40$ & $0.86(0.52-1.42)$ & 0.55 & $1.02(0.58-1.80)$ & 0.94 \\
\hline \multicolumn{5}{|c|}{ Hyaluronic acid level (ng/nl) } \\
\hline$<50$ & & & & \\
\hline $50-190$ & $0.91(0.46-1.78)$ & 0.78 & $1.35(0.62-2.93)$ & 0.44 \\
\hline$\geq 190$ & $0.81(0.38-1.71)$ & 0.58 & $1.80(0.75-4.25)$ & 0.19 \\
\hline
\end{tabular}

progression [31]. Thus, we hypothesized that increased HA levels would be correlated with clinicopathological parameters in HCC and with patient prognosis.

In the present series, the serum HA level was examined in 156 HCC patients, including those with normal liver function, non-viral hepatic dysfunction, viral chronic hepatitis and cirrhosis. The patients were divided into 3 groups according to their serum HA levels. The cutoff values for these groups were based on the normal serum HA level $(50 \mathrm{ng} / \mathrm{ml})$, as defined by previous data, and the median value of the serum HA levels in our se- ries $(190 \mathrm{ng} / \mathrm{ml})$. In our previous study, 150 and 200 $\mathrm{ng} / \mathrm{ml}$ were useful cut-off values for poor postoperative outcomes. In addition, other studies used 150 or 200 $\mathrm{ng} / \mathrm{ml}$ as serum HA level cut-off values for predicting postoperative complications $[14,32,33]$. The value of 190 $\mathrm{ng} / \mathrm{ml}$ is an appropriate value to distinguish between mild and severe liver damage.

Other reports have shown that the serum HA level is increased because of liver injury, viral chronic hepatitis and poor liver function [34,35]. Because they may have poor liver function, HCC patients with increased HA 
level might undergo a less extensive hepatectomy than patients with normal or mildly increased HA levels. The only tumor biological parameter with which the serum HA level was associated in this study was the number of tumors. Other specific biomarkers, such as AFP or PIVKA-II levels, were closely correlated with the number, size, vascular involvement or stage of tumors [36]. Our results showed only a weak association between the serum HA level and tumor progression. The serum HA level was not related to tumor recurrence or the relapse-free period. Obayashi et al. reported that HA was increased in ovarian adenocarcinoma, [37] which suggests there is a different relationship between serum HA and HCC as well as adenocarcinoma. In the present study, there was no significant correlation between the serum HA level and the levels of AFP or PIVKA-II. If the serum HA level correlates tumor development, the mechanism of tumor progression would be different from that of adenocarcinomas. However, the AFP level might be correlated with the degree of chronic hepatitis [38]. Measurement of the level of AFP was not a good indicator of liver injury; measurement of HA levels was more reliable to predict liver injury and patient survival.

In agreement with the present study, Chongsrisawat et $a l$. reported that an increased HA level is associated with massive postoperative ascites [39]. Massive persistent ascites, liver failure and intra-abdominal infection could potentially occur after liver resection, which may influence hospital stay or early and late mortality $[40,41]$. The serum HA level correlated with hepatic ATP levels and mortality rate after extensive hepatectomy in rats [42]. Ogata et al. reported that preoperative serum HA concentrations $>200 \mathrm{ng} / \mathrm{ml}$ were associated with the inhibition of hepatic regeneration after hepatectomy [16]. Because major hepatectomy itself causes an increased risk of these postoperative complications, it would be difficult to determine extent of major hepatectomy in patients with a high HA level [43].

In the present study, a univariate analysis found that the serum HA level was not associated with tumor recurrence but was associated with overall survival. This result indicates that increased HA might not reflect tumor progression itself. We hypothesized that decreased liver function or liver injury due to postoperative hepatic complications might induce tumor progression or new carcinogenesis because of decreased host immunity or increased response to hepatitis. In the present study, only cancer death, not unrelated death, was used to measure the prognosis for overall survival. Liver injury, indicated by increased HA level, might be related to patient prognosis after tumor relapse. A multivariate analysis showed that increased HA level was not significantly associated with either tumor-free or overall survival. Thus, an asso- ciation of HA with tumor progression would be weak. Obayashi et al. and others reported that the activity of the HA protein complex was associated with cancer growth [37]. This marker of non-parenchymal function is a useful candidate for predicting prognosis in $\mathrm{HCC}$ patients.

In conclusion, we conducted a retrospective analysis of the outcomes in $156 \mathrm{HCC}$ patients who received curative hepatectomy, including an analysis of the relationship between the preoperative HA level and the outcome. The serum HA concentration was correlated with poor liver function, multiple $\mathrm{HCC}$ and postoperative complications in HCC patients with liver disease. The serum HA level was associated with overall survival in a univariate analysis, but the HA level was not an independent prognostic factor in a multivariate analysis. Our results suggest that serum HA might mildly reflect the progression of HCC and survival in HCC patients.

\section{REFERENCES}

[1] H. Nordenstedt, D. L. White and H. B. El-Serag, "The Changing Pattern of Epidemiology in Hepatocellular Carcinoma," Digestive and Liver Disease, Vol. 42 No. 3, 2010, pp. 206-214. doi:10.1016/S1590-8658(10)60507-5

[2] G. Fattovich, T. Stroffolini, I. Zagni, et al., "Hepatocellular Carcinoma in Cirrhosis: Incidence and Risk Factors," Gastroenterology, Vol. 127, No. 5, 2004, pp. 35-50. doi:10.1053/j.gastro.2004.09.014

[3] B. Guiu, A. Minello, V. Cottet, et al., "A 30-Year, Population-Based Study Shows Improved Management and Prognosis of Hepatocellular Carcinoma," Clinical Gastroenterology and Hepatology, Vol. 8, No. 11, 2010, pp. 986-991. doi:10.1016/j.cgh.2010.07.018

[4] A. M. Di Bisceglie, "Issues in Screening and Surveillance for Hepatocellular Carcinoma," Gastroenterology, Vol. 127, No. 5, 2004, pp. 104-107. doi:10.1053/j.gastro.2004.09.022

[5] R. W. Pang, J. W. Joh, P. J. Johnson, et al., "Biology of Hepatocellular Carcinoma," Annals of Surgical Oncology, Vol. 15, No. 4,2008, pp. 962-971. doi:10.1245/s10434-007-9730-Z

[6] M. C. Yu, K. M. Chan, C. F. Lee, et al., "Alkaline Phosphatase: Does It Have a Role in Predicting Hepatocellular Carcinoma Recurrence?" Journal of Gastrointestinal Surgery, Vol. 15, No. 8, 2011, pp. 1440-1449. doi:10.1007/s11605-011-1537-3

[7] T. Yang, J. Zhang, J. H. Lu, et al., "Risk Factors Influencing Postoperative Outcomes of Major Hepatic Resection of Hepatocellular Carcinoma for Patients with Underlying Liver Diseases," World Journal of Surgery, Vol. 35, No. 9, 2011, pp. 2073-2082. doi:10.1007/s00268-011-1161-0

[8] F. Manizate, S. P. Hiotis, D. Labow, et al., "Liver Functional Reserve Estimation: State of the Art and Relevance for Local Treatments: The Western Perspective," Journal of Hepato-Biliary-Pancreatic Surgery, Vol. 17, No. 4, 
2010, pp. 385-388. doi:10.1007/s00534-009-0228-x

[9] A. Nanashima, K. Tanaka, H. Yamaguchi, et al., "Fibrosis and Inflammatory Activity in Noncancerous Tissue and Mitotic Index of Cancer Tissue in Patients with Hepatocellular Carcinoma: Relationship to Clinicopathological Factors and Prognosis after Hepatic Resection," Digestive Diseases and Sciences, Vol. 48, No. 8, 2003, pp. 1517-1522. doi:10.1023/A:1024759606402

[10] A. Nanashima, T. Abo, K. Hamasaki, et al., "Perioperative Non-Tumorous Factors Associated with Survival in HCC Patients Who Underwent Hepatectomy," Anticancer Research, Vol. 31, No. 12, 2011, pp. 4545-4551.

[11] A. Nanashima, N. Taura, T. Abo, et al., "Tumor Marker Levels before and after Curative Treatment of Hepatocellular Carcinoma as Predictors of Patient Survival," Digestive Diseases and Sciences, Vol. 56, No. 10, 2011, pp. 3086-3100. doi:10.1007/s10620-011-1796-6

[12] G. Ramadori, G. Zohrens, M. Manns, et al., "Serum Hyaluronate and Type III Procollagen Aminoterminal Propeptide Concentration in Chronic Liver Disease. Relationship to Cirrhosis and Disease Activity," European Journal of Clinical Investigation, Vol. 21, No. 3, 1991, pp. 323-330. doi:10.1111/j.1365-2362.1991.tb01377.x

[13] H. Yoshidome, M. Miyazaki, H. Shimizu, et al., "Obstructive Jaundice Impairs Hepatic Sinusoidal Endothelial Cell Function and Renders Liver Susceptible to Hepatic Ischemia/Reperfusion," Journal of Hepatology, Vol. 33, No. 1, 2000, pp. 59-67. doi:10.1016/S0168-8278(00)80160-9

[14] A. Nanashima, H. Yamaguchi, K. Tanaka, et al., "Preoperative Serum Hyaluronic Acid Level as a Good Predictor of Posthepatectomy Complications," Surgery Today, Vol. 34, No. 11, 2004, pp. 913-919. doi:10.1007/s00595-004-2845-y

[15] A. Nanashima, S. Tobinaga, T. Abo, et al., "Reducing the Incidence of Post-Hepatectomy Hepatic Complications by Preoperatively Applying Parameters Predictive of Liver Function," Journal of Hepato-Biliary-Pancreatic Surgery, Vol. 17, No. 6, 2010, pp. 871-878. doi:10.1007/s00534-010-0281-5

[16] T. Ogata, K. Okuda, T. Ueno, et al., "Serum Hyaluronan as a Predictor of Hepatic Regeneration after Hepatectomy in Humans," European Journal of Clinical Investigation, Vol. 29, No. 9, pp. 778-785.

[17] Liver Cancer Study Group of Japan, "Stage. The General Rules for the Clinical and Pathological Study of Primary Liver Cancer," 4th Edition, Kanehara \& Co. Ltd., Tokyo, 2000, p. 19.

[18] R. G. Knodell, K. G. Ishak, W. C. Black, et al., "Formulation and Application of a Numerical Scoring System for Assessing Histological Activity in Asymptomatic Chronic Active Hepatitis," Hepatology, Vol. 1, No. 5, 1981, pp. 431435. doi:10.1002/hep.1840010511

[19] J. A. Marrero, Z. Feng, Y. Wang, et al., "Alpha-Fetoprotein, Des-Gamma Carboxyprothrombin, and Lectin-Bound Alpha-Fetoprotein in Early Hepatocellular Carcinoma," Gastroenterology, Vol. 137, No. 1, 2009, pp. 110-118. doi:10.1053/j.gastro.2009.04.005
[20] M. Donati, G. Brancato and A. Donati, "Clinical Biomarkers in Hepatocellular Carcinoma (HCC)," Front Biosci (School Ed), Vol. 2, No. 1, 2010, pp. 571-577. doi: $10.2741 / \mathrm{s} 86$

[21] G. Malaguarnera, M. Giordano, I. Paladina, et al. "Serum Markers of Hepatocellular Carcinoma," Digestive Diseases and Sciences, Vol. 55, No. 10, 2010, pp. 2744-2755. doi:10.1007/s10620-010-1184-7

[22] H. Okuda, T. Nakanishi, K. Takatsu, et al., "Clinicopathologic Features of Patients with Hepatocellular Carcinoma Seropositive for Alpha-Fetoprotein-L3 and Seronegative for Des-Gamma-Carboxy Prothrombin in Comparison with Those Seropositive for Des-Gamma-Carboxy Prothrombin Alone," Journal of Gastroenterology and Hepatology, Vol. 17, No. 7, 2002, pp. 772-778. doi:10.1046/j.1440-1746.2002.02806.x

[23] N. Kokudo and M. Makuuchi, "Evidence-Based Clinical Practice Guidelines for Hepatocellular Carcinoma in Japan: The J-HCC Guidelines," Journal of Gastroenterology, Vol. 44 No. 19, 2009, pp. 119-121. doi:10.1007/s00535-008-2244-Z

[24] T. Koh, H. Taniguchi, H. Katoh, et al., "Are Both PIVKA-II and Alpha-Fetoprotein Necessary in FollowUp Management after Hepatic Resection for Hepatocellular Carcinoma?" Hepatogastroenterology, Vol. 49, No. 48, 2002, pp. 1615-1618.

[25] N. Kanazumi, S. Takeda, S. Inoue, et al., "PIVKA-II during Perioperative Period in Patients with Hepato-BiliaryPancreatic Diseases," Hepatogastroenterology, Vol. 47, No. 36, 2000, pp. 1695-1699.

[26] A. Nanashima, Y. Sumida, T. Abo, et al., "Modified Japan Integrated Staging Is Currently the Best Available Staging System for Hepatocellular Carcinoma Patients Who Have Undergone Hepatectomy," Journal of Gastroenterology, Vol. 41, No. 3, 2006, pp. 250-256. doi:10.1007/s00535-005-1751-4

[27] B. Mínguez and A. Lachenmayer, "Diagnostic and Prognostic Molecular Markers in Hepatocellular Carcinoma," Disease Markers, Vol. 31, No. 3, 2011, pp. 181-190.

[28] T. Masuda and E. Miyoshi, "Cancer Biomarkers for Hepatocellular Carcinomas: From Traditional Markers to Recent Topics," Clinical Chemistry and Laboratory Medicine, Vol. 49, No. 6, 2011, pp. 959-966. doi:10.1515/cclm.2011.152

[29] N. A. Sadik, A. Ahmed and S. Ahmed, "The Significance of Serum Levels of Adiponectin, Leptin, and Hyaluronic Acid in Hepatocellular Carcinoma of Cirrhotic and Noncirrhotic Patients," Human \& Experimental Toxicology, Vol. 31, No. 4, 2012, pp. 311-321. doi:10.1177/0960327111431091

[30] L. Meléndez-Alafort, A. Nadali, E. Zangoni, et al., "Biokinetic and Dosimetric Studies of 188Re-Hyaluronic Acid: A New Radiopharmaceutical for Treatment of Hepatocellular Carcinoma," Nuclear Medicine and Biology, Vol. 36, No. 6, 2009, pp. 693-701.

[31] T. Mizuguchi, M. Nagayama, M. Meguro, et al., "Prognostic Impact of Surgical Complications and Preoperative Serum Hepatocyte Growth Factor in Hepatocellular Car- 
cinomapatients after Initial Hepatectomy," Journal of Gastrointestinal Surgery, Vol. 13, No. 2, 2009, pp. 325333. doi:10.1007/s11605-008-0711-8

[32] H. Wakabayashi, S. Yachida, T. Maeba, et al., "Indications for Portal Vein Embolization Combined with Major Hepatic Resection for Advanced-Stage Hepatocellular Carcinomas. A Preliminary Clinical Study," Digestive surgery, Vol. 17, No. 6, 2000, pp. 587-594. doi:10.1159/000051967

[33] M. R. Schön, J. U. Eisenberg, H. P. Lemmens, et al., "The Correlation of Serum Hyaluronan of Liver Donors with Posttransplant Liver Function," Transplant International, Vol. 7, No. 1, 1994, pp. 128-133.

[34] V. S. Wong, V. Hughes, A. Trull, et al., "Serum Hyaluronic Acid Is a Useful Marker of Liver Fibrosis in Chronic Hepatitis C Virus Infection," Journal of Viral Hepatitis, Vol. 5, No. 3, 1998, pp. 187-192. doi:10.1046/j.1365-2893.1998.00100.x

[35] J. Y. Cheong, D. J. Kim, S. G. Hwang, et al., "Serum Markers for Necroinflammatory Activity in Patients with Chronic Viral Hepatitis and Normal or Mildly Elevated Aminotransferase Levels," Liver International, Vol. 31, No. 9, 2011, pp. 1352-1358. doi:10.1111/j.1478-3231.2011.02570.x

[36] Y. Inagaki, W. Tang, M. Makuuchi, et al., "Clinical and Molecular Insights into the Hepatocellular Carcinoma Tumour Marker Des- $\gamma$-Carboxyprothrombin," Liver International, Vol. 31, No. 1, 2011, pp. 22-35. doi:10.1111/j.1478-3231.2010.02348.x

[37] Y. Obayashi, H. Yabushita, K. Kanyama, et al., "Role of Serum-Derived Hyaluronan-Associated Protein-Hyaluronan Complex in Ovarian Cancer," Oncology Reports, Vol. 19, No. 5, 2008, pp. 1245-1251.
[38] P. Richardson, Z. Duan, J. Kramer, et al., "Determinants of Serum Alpha-Fetoprotein Levels in Hepatitis C-Infected Patients," Clinical Gastroenterology and Hepatology, Vol. 10, No. 4, 2012, pp. 428-433. doi:10.1016/j.cgh.2011.11.025

[39] V. Chongsrisawat, P. Kongtawelert, W. Tongsoongnoen, et al., "Serum Hyaluronan as a Marker Reflecting the Severity of Cirrhosis and Portal Hypertension in Postoperative Biliary Atresia," Pediatric Surgery International, Vol. 20, No. 10, 2004, pp. 773-777. doi:10.1007/s00383-004-1141-7

[40] S. Virani, J. S. Michaelson, M. M. Hutter, et al., "Morbidity and Mortality after Liver Resection: Results of the Patient Safety in Surgery Study," Journal of the American College of Surgeons, Vol. 204, No. 6, 2007, pp. 12841292. doi:10.1016/j.jamcollsurg.2007.02.067

[41] K. M. Chan, C. F. Lee, T. J. Wu, et al., "Adverse Outcomes in Patients with Postoperative Ascites after Liver Resection for Hepatocellular Carcinoma," World Journal of Surgery, Vol. 36, No. 2, 2012, pp. 392-400. doi:10.1007/s00268-011-1367-1

[42] K. Chijiiwa, M. Watanabe, Y. Hachiya, et al., "Serum Hyaluronic Acid Level Reflects Volume and ATP Levels of the Liver after Extended Hepatectomy with and without Preoperative Portal Vein Occlusion," Journal of Surgical Research, Vol. 72, No. 2, 1997, pp. 107-111. doi:10.1006/jsre.1997.5166

[43] K. P. Massimino, K. J. Kolbeck, C. K. Enestvedt, et al., "Safety and Efficacy of Preoperative Right Portal Vein Embolization in Patients at Risk for Postoperative Liver Failure Following Majorright Hepatectomy," $H P B(O x-$ ford), Vol. 14, No. 1, 2012, pp. 14-19. doi:10.1111/j.1477-2574.2011.00402.x 